\title{
Ventricular catheter development: past, present, and future
}

\author{
Sofy H. Weisenberg, BSc, ${ }^{1}$ Stephanie C. TerMaath, PhD,, Chad E. Seaver, MSc, ${ }^{1}$ and \\ James A. Killeffer, MD² \\ ${ }^{1}$ Institute of Biomedical Engineering; and 2Division of Neurosurgery, Department of Surgery, Graduate School of Medicine, \\ University of Tennessee, Knoxville, Tennessee
}

\begin{abstract}
Cerebrospinal fluid diversion via ventricular shunting is the prevailing contemporary treatment for hydrocephalus. The CSF shunt appeared in its current form in the 1950s, and modern CSF shunts are the result of 6 decades of significant progress in neurosurgery and biomedical engineering. However, despite revolutionary advances in material science, computational design optimization, manufacturing, and sensors, the ventricular catheter (VC) component of CSF shunts today remains largely unchanged in its functionality and capabilities from its original design, even though VC obstruction remains a primary cause of shunt failure. The objective of this paper is to investigate the history of VCs, including successful and failed alterations in mechanical design and material composition, to better understand the challenges that hinder development of a more effective design.
\end{abstract}

http://thejns.org/doi/abs/10.3171/2015.12.JNS151181

KEY WORDS ventricular catheter; design; materials; history; hydrocephalus; shunt

$\mathrm{T}$ HE most common treatment for both congenital and acquired hydrocephalus is the placement of a CSF shunt that diverts excess CSF from the ventricles to a part of the body in which it can be readily absorbed. While effective, newly placed shunts require on average 2 to 4 revision surgeries within the first 10 years after implantation. ${ }^{57,62}$ A large percentage of these revisions occur within the 1 st year after placement, and most ${ }^{62}$ are required within the first 2 years..$^{26,42,84}$ Ventricular catheter (VC) obstruction is the cause of nearly one-third of shunt failures (Fig. 1), making it the most common reason for revision surgery. $7,69,84$

Reducing shunt failure rates remains a major goal of shunt development, and improving VC performance would constitute a major step in that direction. Although several reviews have addressed the historical development of the shunt system as a whole, $, 3,17,19,46,53,60$ none to date have focused specifically on the VC. The object of this paper is to highlight the evolution of VCs in order to inform modern efforts at improving their effectiveness and reliability.

\section{Historical Overview of the Pre-Shunt Era}

Following Joseph Lister's discovery of the benefits of aseptic surgery in the $1860 \mathrm{~s},{ }^{48}$ methods involving cannulation of the ventricles became feasible and were attempted with varying degrees of success. The first sterile ventricular puncture and external ventricular drain (EVD) insertion was performed in 1881 by Carl Wernicke. ${ }^{40}$ External drainage via catheter-like devices, including horsehair, silk, and catgut wicks, became quite popular during the late 19th century. ${ }^{68}$ However, in response to the risks posed by open drainage, attempts were made at the beginning of the 20th century to introduce mechanisms for internal CSF diversion. ${ }^{65}$ Rerouting CSF from the ventricles to the subdural space was first accomplished in 1893 by the Polish-Austrian surgeon Jan Mikulicz-Radecki, who inserted a mass of glass wool in the shape of a nail into the ventricles of a child. ${ }^{3,15}$ The child not only survived the procedure, but progression of the hydrocephalus in this case was effectively stopped. In the latter part of the 1890 s, gold

ABBREVIATIONS EVD = external ventricular drain; PDMS = polydimethylsiloxane; $V C=$ ventricular catheter.

SUBMITTED May 29, 2015. ACCEPTED December 3, 2015.

INCLUDE WHEN CITING Published online March 4, 2016; DOI: 10.3171/2015.12.JNS151181. 


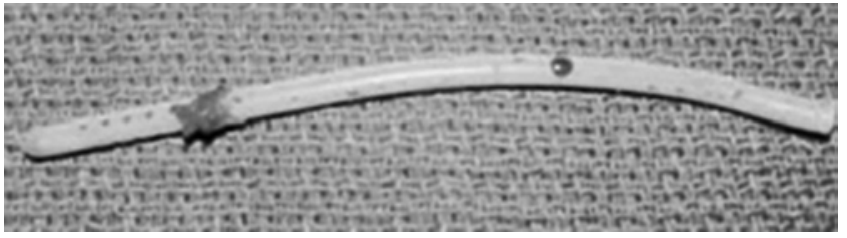

FIG. 1. Photograph of an occluded VC, showing debris accumulation around proximal hole set. Modified with permission from Lin et al: J Neurosurg 99:426-431, 2003.

tubes $^{35}$ and bundled strands of catgut ${ }^{71}$ were also used for such "ventriculo-subdural" shunts. In 1903, Nicholas Senn performed the first recorded surgery using a perforated rubber tube, a crude predecessor of the modern VC, for subcutaneous drainage of CSF (Fig. 2) ${ }^{65}$

Most of these early attempts ended badly, however, as patients developed fatal infections in addition to the already identified danger of mechanical obstruction. As early as 1899, Adolf Dehler reported failure of an implanted gold tube due to "stoppage." 15 These challenges were not easily addressed by the medicine of the times, and a lack of effective antibiotics made it difficult to combat infections once they were identified. Nevertheless, surgeons practicing between 1908 and 1926 pursued many variations on this type of ventricular drainage including the use of glass tubes, ${ }^{2}$ split-ended silver tubes sewn to the pericranium, ${ }^{44}$ and even strips of omentum ${ }^{43}$ (peritoneal tissue). In 1917 the neurological surgeon William Sharpe reported some success with the use of linen threads. Of the 41 patients in Sharpe's clinical study, 28 survived the procedure, and 22 of these showed marked improvement. ${ }^{66}$

Transplanted human or calf blood vessels were also implanted in various experiments and routed to the superior sagittal sinus, the jugular vein, or the common facial veins..$^{15}$ In this case, the valves in the veins were used to prevent backflow and direct the CSF out of the ventricles. These early decades of the 20th century also saw many other innovations in the treatment of hydrocephalus, including the first descriptions of Kocher's point and Frazier's point, the optimal cranial sites for catheter insertion that are still used today. ${ }^{56}$ Although these early attempts created the foundation for the modern VC, the mid-20th century would see the first truly successful breakthroughs in its implementation.

\section{Beginnings of Modern VC Development (1950-1980)}

Arne Torkildsen developed the most notable precursor to the modern internalized shunt. The Torkildsen shunt furthered the widespread use of implanted catheters during the 1940s and 1950s and, until the introduction of ventriculoatrial and ventriculoperitoneal shunts, was the most widely used means of CSF diversion. Introduced in 1939, it consisted of a rubber catheter used to cannulate the lateral ventricle and divert CSF to the cisterna magna in cases of noncommunicating hydrocephalus. ${ }^{77}$ Because the Torkildsen shunt used a catheter to simply bridge 2 CSF-filled cavities, one favorable outcome was a very low incidence of catheter obstruction, which would come to be a serious issue in more complex shunt systems. ${ }^{29,52,76}$

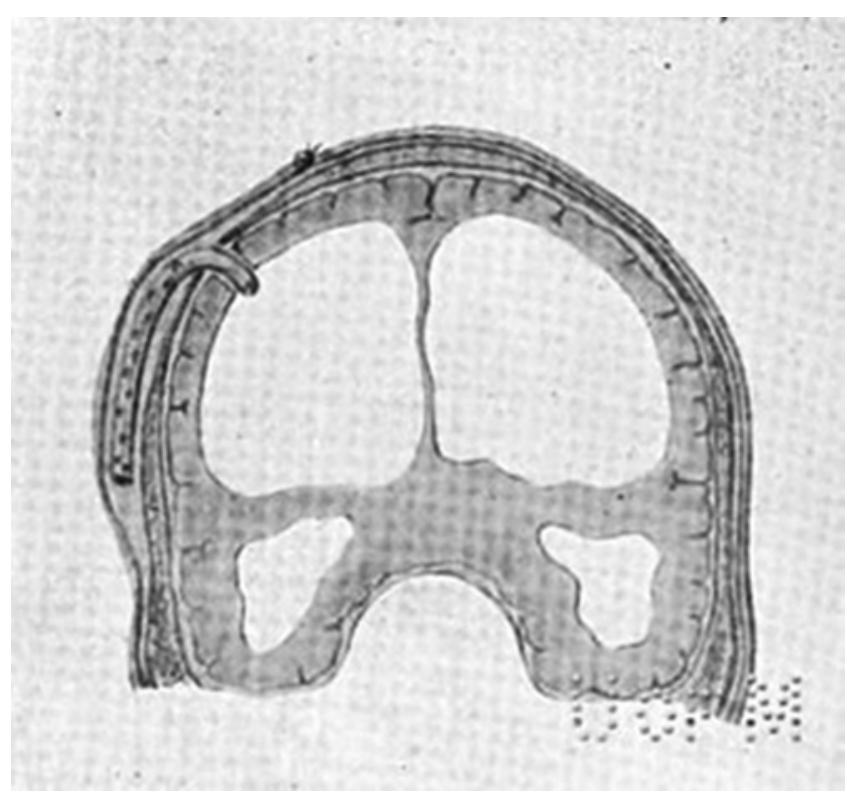

FIG. 2. The first recorded use of a perforated rubber tube as a shunt for subcutaneous drainage of CSF. Performed by surgeon Nicholas Senn, 1903. Reproduced from Senn: Alienist Neurol 24:316-324, 1903. Public domain.

The advent of the modern, fully internalized shunt system is generally credited to the innovations of Frank Nulsen and Eugene Spitz. In their landmark 1951 paper, they described the first successful attempt to treat hydrocephalus by means of a ventriculojugular shunt. ${ }^{55} \mathrm{Al}-$ though this paper is commonly credited with introducing the first 1-way flow-regulating device in a ventriculojugular shunt, it also describes the use of a specific 12-Fr soft rubber catheter inserted into the ventricle.

In the meantime, the search for improved biomaterials continued. Franc D. Ingraham, a pioneer in pediatric neurosurgery, published a report in 1947 on the use of polyethylene as a new synthetic plastic for use in neurosurgery, suggesting that it could be safely implanted into the tissues of the ventricular system. ${ }^{38}$ Until this period, rubber tubing had been the standard material used in the Torkildsen shunt and in the first Nulsen-Spitz shunt. Ingraham's findings led to the choice of polyethylene as the material for a new generation of VCs. Polyethylene, however, ultimately proved to be an unsatisfactory shunt material due to complications at the distal end of the device, thus prompting a search for a better polymer. ${ }^{1}$ This search led to polydimethylsiloxane (PDMS), or silicone rubber. Originally investigated as an insulation material for electric motors and generators, PDMS was studied as a potential biomaterial throughout the 1940s due to its elasticity, thermal stability, and bio-inertness. ${ }^{13}$

In 1948, the first successful replacement of a male urethra by a narrow silicone catheter was accomplished ${ }^{16}$ leading to the consideration of other clinical applications for silicone catheters. In 1957, Robert Pudenz reported on the successful use of a ventriculoatrial shunt made completely of silicone rubber. ${ }^{59}$ The first silicone ventriculoperitoneal shunt was implanted in 1958 by Richard Ames, and 9 years later he reported promising results after per- 
forming 120 additional procedures using silicone tubing. ${ }^{1}$ This period marked an increase in the popularity of silicones, in part due to their prominent use in the Apollo space program, and there was a significant transition to the almost exclusive use of medical-grade silicone (marketed as Silastic by the Dow-Corning Corporation) tubing in shunts, and specifically in VCs (Fig. 3).

With this successful shift in materials, engineers began to focus on how to solve the other problems inherent in shunts, particularly that of VC obstruction. In his 1969 report ${ }^{29}$ on the nature of VC hole occlusion, Salomon Hakim identified the main cause of obstruction as the invasion of choroid plexus via the catheter holes. Hakim, as well as other neurosurgeons, attempted to remedy this problem by modifying VC architecture. He introduced the "shepherd crook" or J-shaped catheter, the tip of which was curved, with holes on the inside of the curve so as to distance them from invasive fronds of choroid plexus. Despite some early recorded success with this design, the experience with this particular catheter was disappointing overall, as elongated filaments of choroid plexus were still able to reach the catheter tip, obstructing the orifices. ${ }^{29,62}$

Another design was the Portnoy flanged catheter, introduced in $1971 .^{58}$ Although seriously flawed, this design has seen relatively prolonged use in the neurosurgical community. The original design included several soft silicone rubber "umbrella" flanges positioned between the catheter holes (Fig. 4); these were intended to protect the holes from brain parenchyma during insertion and from invasion of choroid plexus in the ventricles. ${ }^{28}$ The flanges folded back over the holes during insertion and opened once the catheter tip was inside the ventricle. Although there was some early clinical evidence that this design reduced catheter occlusion, and therefore the need for shunt revision, ${ }^{28}$ this initial conclusion was later reexamined in a report that found evidence of a higher risk of proximal occlusion with long-term use of the flanged design. ${ }^{66}$ Moreover, the presence of the flanges was detrimental to those patients who did require revision, in that the flanges made

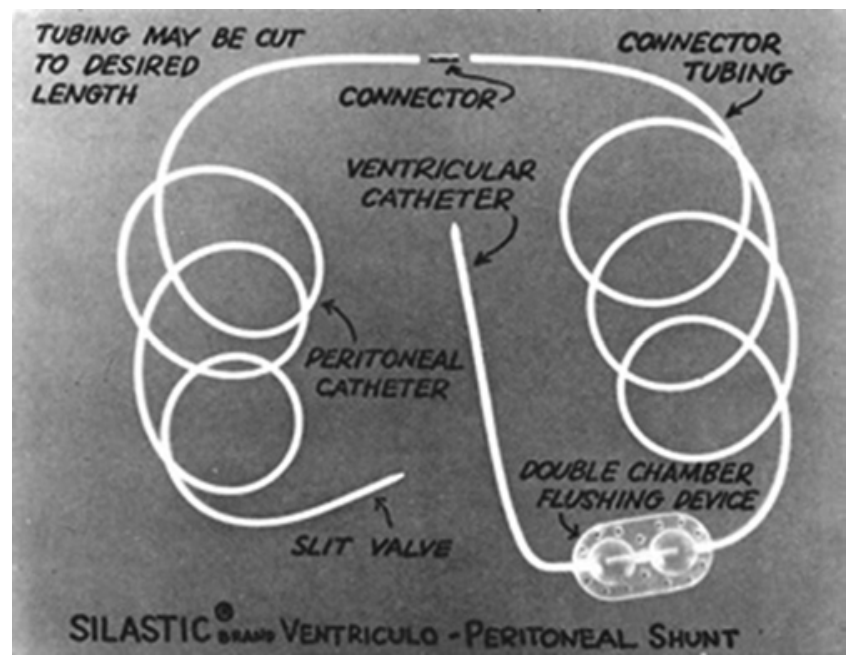

FIG. 3. Photograph of a Silastic shunt system with various components labeled. Reprinted with permission from Ames: J Neurosurg 27:525529, 1967.

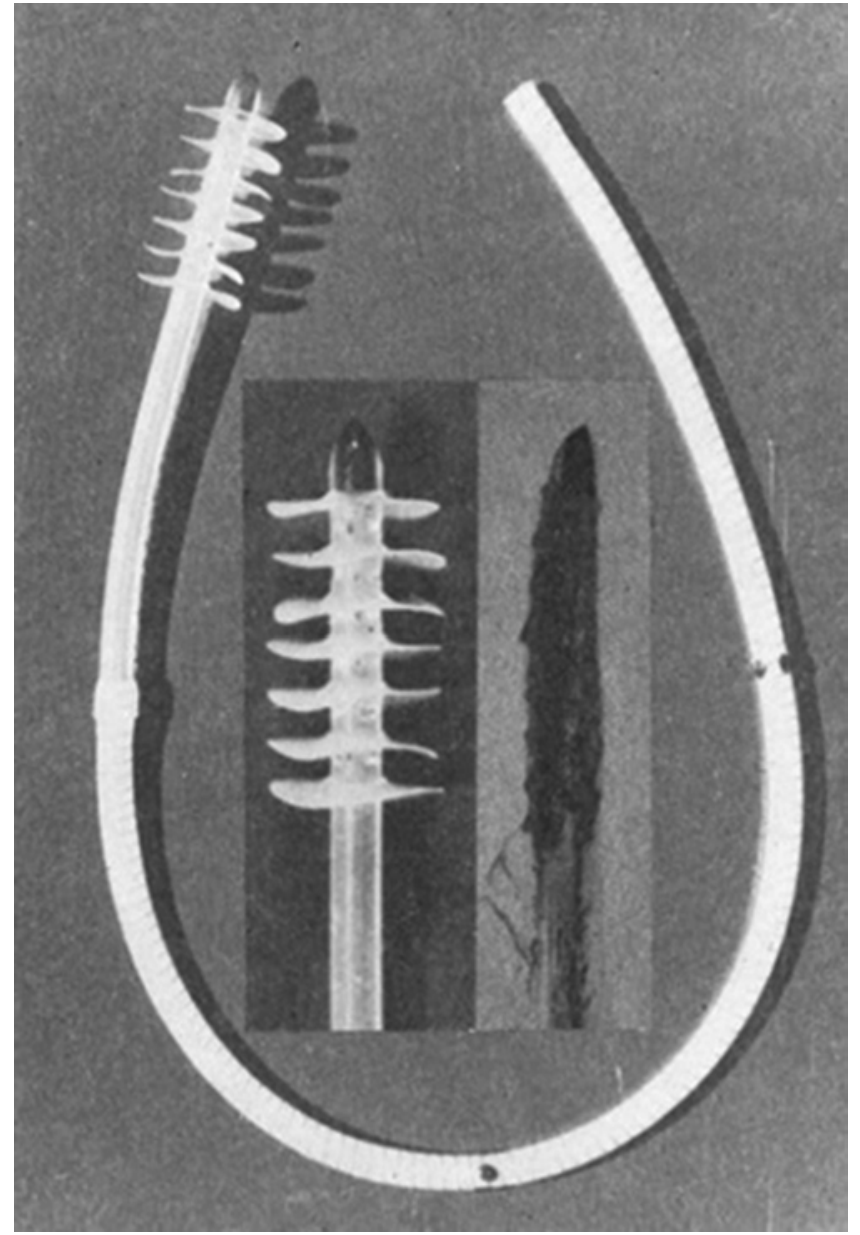

FIG. 4. Photograph of Portnoy's flanged VC. Center Left: Close-up of the catheter tip showing silicone rubber flanges placed directly in between the holes. Center Right: The catheter tip after insertion into gelatin, demonstrating the flanges folded back over the holes. Reprinted with permission from Portnoy: J Neurosurg 34:702-703, 1971.

catheter removal extremely dangerous by creating a risk of hemorrhage and permanent damage to surrounding brain tissue.

\section{Maturing of the Modern VC (1980-2005)}

Root cause investigation of VC failures during the 1980s offered new insights into the mechanisms of shunt failure, particularly occlusion, and new countermeasures to circumvent problems were devised. In $1981 \mathrm{Go}$ et al. ${ }^{26}$ histologically examined explanted catheters and identified obstructions related to dead cells that developed within 1 month of implant and choroid plexus invasion occurring within 3-6 months. In 1982, Sekhar et al. ${ }^{64}$ identified adsorbed tissue types including connective, inflammatory, granulomatous, glial, and choroid plexus as sources of occlusion. Characterization of obstructions and obstructed flow through VCs was also studied via mathematical models ${ }^{63}$ and shunt reservoir taps ${ }^{67}$ and a number of investigations of materials and methods to circumvent this problem were subsequently undertaken. A 1982 design included a floating catheter that included an air cell integrated into 
the catheter. This was intended to provide some distance between the ventricle walls and the center of the ventricle in order to avoid significant choroid plexus contact and invasion..$^{54}$ Other patented approaches similarly attempted to protect the catheter holes from occlusion (Fig. 5).

Several modifications in material were also experimentally evaluated during this period. One of the most notable investigations included the testing of what eventually developed into Codman's Bactiseal antimicrobial catheter. In 1981, Bayston and Milner ${ }^{5}$ evaluated the addition of various antibiotics to silicone catheters as a means of reducing obstruction due to microorganism colonization, which was believed to develop from skin bacteria (e.g., Staphylococcus albus) proximal to catheter incision sites. This study evaluated various antibiotics introduced at 4 different process steps of silicone vulcanization. Other patents ${ }^{4,50}$ issued in the 1980 s used meshlike porous materials, formed by processes such as ion beam sputter-etching, ${ }^{4}$ to promote a more favorable biological response. A further investigation presented by Medow ${ }^{49}$ also suggested that such a catheter material, which is permeable to most components of CSF but not to prokaryotic or eukaryotic cells, could help prevent catheter obstruction.

In contrast to the silicone (PDMS) catheters that were widely used during the 1980s, Wong et al., ${ }^{82}$ in a 1991 publication, evaluated construction of catheters from polyhydroxyethylmethacrylate (pHEMA), a semi-wettable polymer that is essentially a gel-like material in water. pHEMA materials, which began to be studied for biocompatibility in the $1960 \mathrm{~s},{ }^{80}$ reportedly hinder protein adsorption and cell binding by offering a strongly hydrophilic surface composition. Although Wong's study showed intriguing

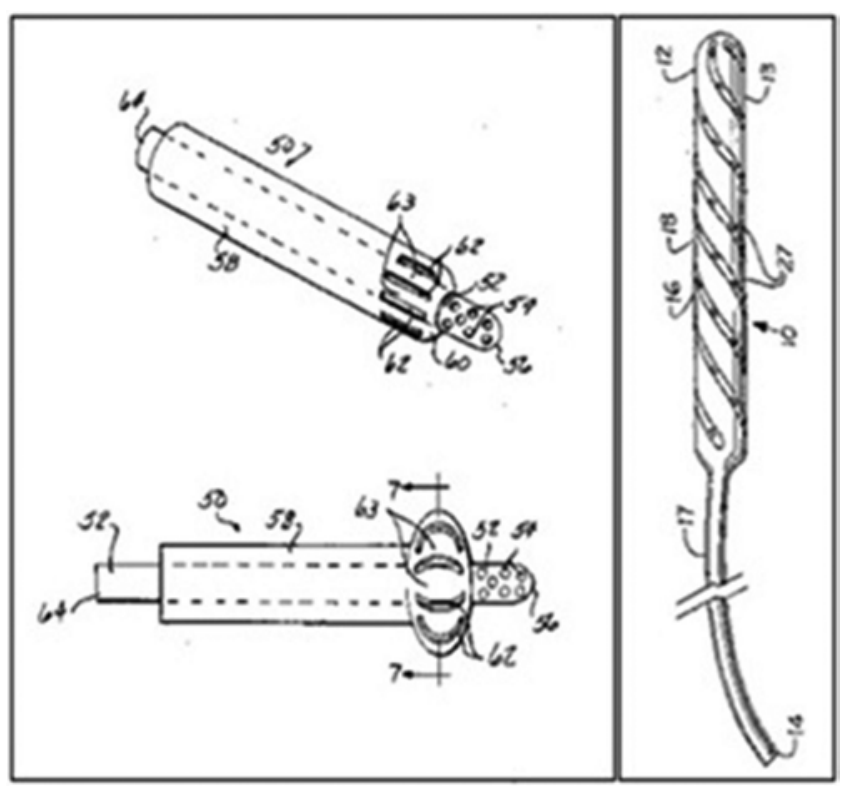

FIG. 5. Patents for VC designs. Left: A catheter tip featuring an inflatable "cuff" to aid in hole positioning within the ventricle, away from the choroid plexus. From Corbett JE, inventor: Ventricular catheter. US patent 4655745 A. April 7, 1987. Right: Catheter featuring holes sitting in a helical protective groove, 1990. From Ruzicka P, Ruzicka M, inventors: Cerebrospinal fluid shunt system. US patent 4950232 A. August 21, 1990. promise for pHEMA construction, the device design used in the study consisted of a subdural shunt configuration, in which fibrous subdural catheter encapsulation developed. Consequently, the evaluation was inconclusive and the possible benefits of pHEMA as an antifouling catheter material were obscured. In 1992, Gower et al. ${ }^{27}$ evaluated expanded polytetrafluoroethylene (e-PTFE) as another alternative to silicone. Commonly known as Gore-Tex, this material is currently used as a long-term implant in vocal cord treatments, arterial grafts, orthopedic joint implants, and facial plastic surgery because it is associated with minimal adverse tissue reactions. However, Gower found that, although e-PTFE is successful in other applications and is safe as a cerebral implant, the porosity of the material, which is on the order of only $5 \mu \mathrm{m}$, unfortunately permitted tissue ingrowth and catheter obstruction.

An additional material modification included a VC coated with polyvinylpyrrolidone (PVP) for surface functionalization. Introduced in 1995 by Medtronic under the brand name BioGlide, PVP is a hydrophilic substance that can covalently bond to the surface of silicone as a hydrogel, providing a "water jacket" by virtue of water absorption and thereby creating a slippery surface. A 2004 study showed that such functionalization indeed provides some resistance to bacterial colonization. ${ }^{10}$ However, the BioGlide's surface was so slippery that the catheter lumen would sometimes slip out of the connectors attaching it to the valve in the shunt system, a problem that caused it to be removed from the market in 2010.11,31

At the turn of the millennium, new advances in VCs were introduced by commercial conglomerates, including Johnson \& Johnson and Medtronic. Codman (J\&J) investigated the antimicrobial-impregnated lumens previously researched by Bayston and Milner, and the resulting catheter, branded Bactiseal, was approved by the FDA in 2001. The catheter featured impregnation of 2 antimicrobials, Rifampicin and Clindamycin HCL, into the silicone matrix. ${ }^{72}$ A few years later in 2008, Medtronic introduced extracted silicone catheters, having unpolymerized oligomers removed for treatment in silicone-sensitive patients. ${ }^{20}$

On the design front, a wide variety of proposed catheter geometries were patented during this time, although few were actually adopted for clinical use. Lin et al. published a landmark study ${ }^{47}$ in 2003 that demonstrated, through computational fluid dynamics and experimental validation, that the commonly used 12 - to 32 -hole perforation patterns in VCs make them highly prone to the type of obstructions that cause shunt failure. The study showed that only the most proximal hole sets (those furthest from the catheter tip) actually experience significant flow rates (50\%-75\% of the entire flow volume) during CSF drainage, while the distal holes (those nearest to the tip) have substantially lower flow rates in comparison (Fig. 6). The study suggested that a more uniform flow distribution among the catheter holes could help prevent shunt failure by decreasing the probability of occlusion of the proximal hole sets and that, in the case of a distal hole occlusion, at least some of the functionality of the catheter would be preserved. The resulting improvement was later approved by the FDA and introduced to the market in 2007 as Medtronic's Rivulet catheter. This device uti- 
lizes a configuration of 4 parallel rows comprising holes of decreasing size, with the distal hole set being the largest. The uniformity of flow distribution of this design was verified again more recently in computational simulations by Galarza et al. ${ }^{22,23}$

\section{Contemporary Ventricular Catheters (2005- 2015)}

The last decade of shunt development has seen a renewed interest in $\mathrm{VC}$ design, as well as the incorporation of new materials and coatings. Today, most VCs are made of silicone polymer tubing and are available in straight configurations, which may be cut to the appropriate length intraoperatively, or angled configurations, which have a set length. Inner diameters of the tubing range between $1.0 \mathrm{~mm}$ and $1.6 \mathrm{~mm}$ and outer diameters between $2.1 \mathrm{~mm}$ and $3.2 \mathrm{~mm} .{ }^{19}$ Holes are usually arranged in 3 or 4 rows, equally spaced around the catheter diameter in the 1.0-1.5 $\mathrm{cm}$ nearest the catheter tip, with rows arranged either in parallel or staggered configurations, generally with 4-8 holes in each row. Holes within a row may be the same size, typically measuring between $0.25 \mathrm{~mm}$ and $0.5 \mathrm{~mm}$ at the outer catheter surface, or may change along the length of the row. Many holes feature a conical shape, slightly tapering toward the inner surface. Hole number, size, shape, and spacing vary among the different manufacturers. ${ }^{19,22,23}$

\section{Material Considerations}

Limiting the adhesion of proteins and cells that can cause catheter obstruction or infection has been a primary focus of VC research. Surprisingly, it has been found that high CSF protein concentrations may actually inhibit bacterial adhesion by rendering the generally hydrophobic silicone more hydrophilic. ${ }^{8}$ Protein adsorption alone has not been shown to cause accumulations in large enough amounts to generate occlusion, and the thin albumin film that most often forms may actually serve to improve the biocompatibility of the catheter. ${ }^{9}$ A 2010 report showing that astrocyte adhesion was positively correlated with fluid flow through $\mathrm{VCs}^{33}$ may explain the favorable initial results of experiments evaluating the cell growth characteristics of electrospun polyurethane catheters, which are microporous in nature and would have inherently lower flow rates than most catheters. ${ }^{70}$ Another approach to reducing obstruction is to limit contact of the VC holes with brain tissues during ventricular puncture, so as to avoid the ingestion of parenchymal cells by the catheter. A peelaway sheath technique has been implemented by some neurosurgeons to protect the VC holes from brain debris during insertion. However, a randomized study, performed in 2012 by Kehler et al. ${ }^{41}$ in 177 patients with ventriculoperitoneal shunts, showed no statistically significant difference in the number of obstructions among patients in which a peel-away sheath insertion technique was used.

A focus on catheter surface properties and coatings has also led to recent advances. In 2007, a National Institutes of Health-sponsored workshop on the priorities for hydrocephalus research indicated the need for more in-depth research into the possible benefits of antibiotic-impregnated catheters. ${ }^{81}$ In vitro and preclinical studies have shown

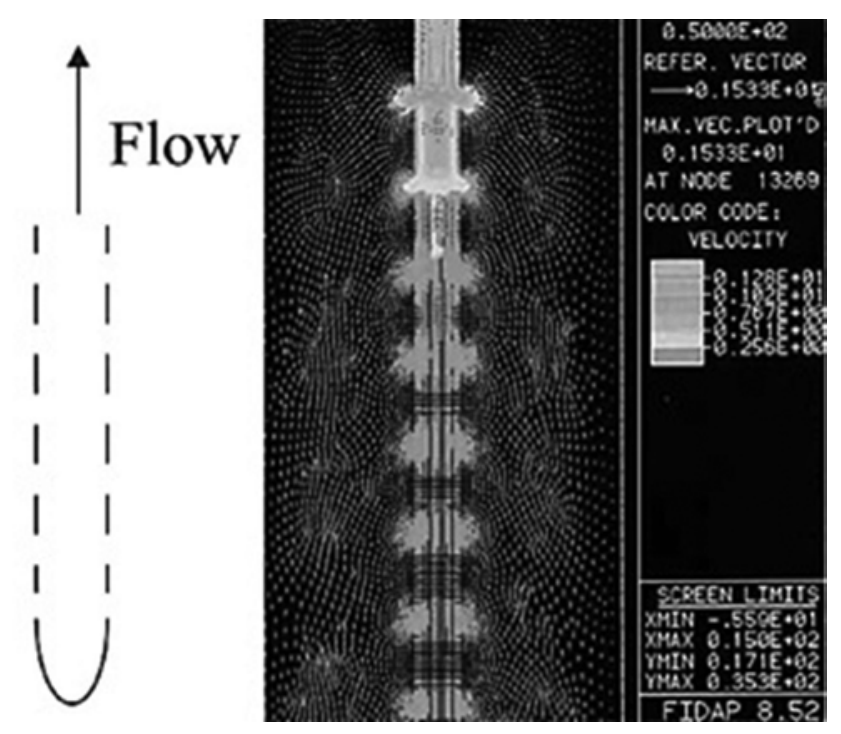

FIG. 6. Image from a 2D computational fluid dynamics study showing most of the flow entering the VC via a proximal hole set (the catheter tip is facing down in the simulated image). Modified with permission from Lin et al: J Neurosurg 99:426-431, 2003.

that various forms of polyethylene glycol, a nondegradable hydrophilic polymer, may reduce protein adsorption and macrophage and astrocyte attachment when used as a catheter coating..$^{32,34}$ The addition of silver nanoparticles to such coated catheters also produced a notable drop in catheter-related infections. ${ }^{34}$ Another suggested improvement is diamond-like carbon coatings that are produced by plasma-assisted chemical vapor deposition. ${ }^{6}$ By acting as an effective ion diffusion barrier, such coatings can protect the patient from ions released from the catheter while at the same time protecting the catheter from the harsh biological environment. The incorporation of other surface-modifying coatings and additives, including surfaces that mimic native extracellular matrix or endothelial cell layers, incorporation of pharmaceuticals, bioactive agents, self-locating fluoro-oligomeric additives, and antithrombogeneic agents, show promise for further investigation. ${ }^{31}$

\section{Design Considerations}

Along with material and surface improvements, inlet hole design may also be a key to improved VC functionality. It has recently been shown that macrophage and astrocyte adhesion to catheters is greater in flowing fluid conditions than in static fluid conditions, making flow rate through each of the holes an important parameter to consider. ${ }^{33}$ In addition to flow rate, the number and size of holes may also affect the rate of cell adhesion. Decreasing the number of inlet holes or the hole diameters causes fluid wall shear stress at the hole surface to increase, and increased shear stress has been linked to increases in cell adhesion (although at the other extreme, very low shear stress may increase cell adhesion as well). ${ }^{30}$ Further investigations into the influence of these factors on obstructions resulting from cell adhesion and inflammatory response are necessary, but changing hole configurations may be an inexpensive way to make meaningful advancements in VC design. The fabrication of these inlet hole configura- 
tions is also of interest since the techniques currently used sometimes result in the creation of inherently rough hole surfaces. Improving these techniques and/or adding secondary manufacturing steps to smooth the hole surfaces, after hole punching processes for example, may help to reduce cell adhesion to these surfaces as well as decrease the incidence of thrombogenesis at the inlet holes. ${ }^{30,31}$

Optimizing hole design and configurations has also been investigated as a means to reduce catheter obstruction. Along with the computational fluid simulations done by Galarza et al..$^{22,23}$ on different catheter configurations, an experimental study published in 2010 by Thomale et al. ${ }^{74}$ examined VCs with substantially fewer perforations. These experimental catheters were designed with a total number of either 4 or 6 holes (as opposed to the more common 12-32 holes) located closer to the catheter tip, thereby reducing the length of the perforated catheter segment. The study was conducted in response to the hypothesis that proximal holes in the catheter may, on occasion, be positioned outside the ventricle, thereby increasing the risk of obstruction, especially in cases of slit-like ventricles. It was demonstrated clinically that catheters with fewer perforation holes, when correctly positioned within the ventricles, are sufficient to maintain shunt function and flow capacities. This finding confirms an earlier study ${ }^{25}$ which argued that the same pressure-flow correlations may be observed in catheters bearing as few as 2 holes as well as those with the standard 32 holes. Both studies suggest that designs utilizing more than 2 holes do not necessarily correlate with improved drainage through the catheter.

Methods of response to VC obstruction have also been improved in recent years. Invasive techniques of catheter recanalization, which require surgical exposure of the catheter, have been investigated over the past 2 decades. These techniques include pulsed laser energy delivered via a flexible optical fiber, ${ }^{12}$ ultrasound waves transmitted over a fine wire, ${ }^{24}$ and percutaneous endoscopic recanalization via electrocautery. ${ }^{56}$ However, focus has more recently turned to finding noninvasive treatments. When an occlusion is suspected, a new noninvasive imaging method combining pulsed laser light and ultrasound techniques has been proposed to allow surgeons to view the occluded catheter through the skull. ${ }^{73}$ Once an occlusion has been identified, another recent study reports that transcutaneous vibration in the $50-$ to $60-\mathrm{Hz}$ range, applied in short intervals, has been shown to maintain in vitro catheter performance and clear catheters that were completely occluded. ${ }^{21}$ In addition, the novel inclusion of MEMS (Micro Electro-Mechanical Systems) in the form of magnetic microactuators, has been studied as another alternative to clear blocked holes. These microactuators may prove advantageous, as they can be controlled noninvasively and require no integrated circuits or power sources. ${ }^{37}$

Some of the recently patented design improvements to VCs have shown more of this novel thinking. One design features a rounded transparent tip that allows the concurrent insertion of an endoscope through the catheter during surgery (Fig. 7 left). ${ }^{18}$ This design can provide continuous visualization for intraoperative navigation of the catheter tip while in the fluid-filled ventricle. The tip's round shape is specifically designed to minimize contact with tissues that could potentially obstruct the view of the implant site. Another configuration features a biocompatible housing made of several components (Fig. 7 right). This housing may be fitted onto a standard catheter to specifically combat the potential for occlusions, particularly those initiated by an inflammatory response..$^{51}$

\section{Future Directions}

Overall, shunt development could benefit from a more holistic approach to VC engineering, taking into consideration the component's biocompatibility, surface properties, surroundings, lifespan, and mechano-fluid dynamics. Evaluating the effectiveness of antimicrobial-impregnated catheters as well as other infection prevention mechanisms should be a priority as these technologies continue to mature. Alongside material advances, design optimization through systematic fluid flow testing of catheter hole configurations, for example, may also prove beneficial and remains a largely underexplored area for improvement.

Another particular emphasis in several recent publications $^{78,79,83}$ has been on the role of VC placement in overall shunt success, especially in patients with smaller or abnormal ventricular anatomy. Achieving optimal positioning with the VC completely surrounded by CSF remains challenging. Radiopaque indicators, typically utilizing barium sulfate or tantalum and incorporated into the VC polymer, are included in most commercially available catheters today and aid in verifying VC positioning. Still, the push for more accurate VC placement processes has certainly had an effect on surgical technology ${ }^{36,39,45,75}$ and may have future effects on VC design.

\section{Conclusions}

Advances in the fields of biomaterials and biomedical engineering have made significant contributions to the

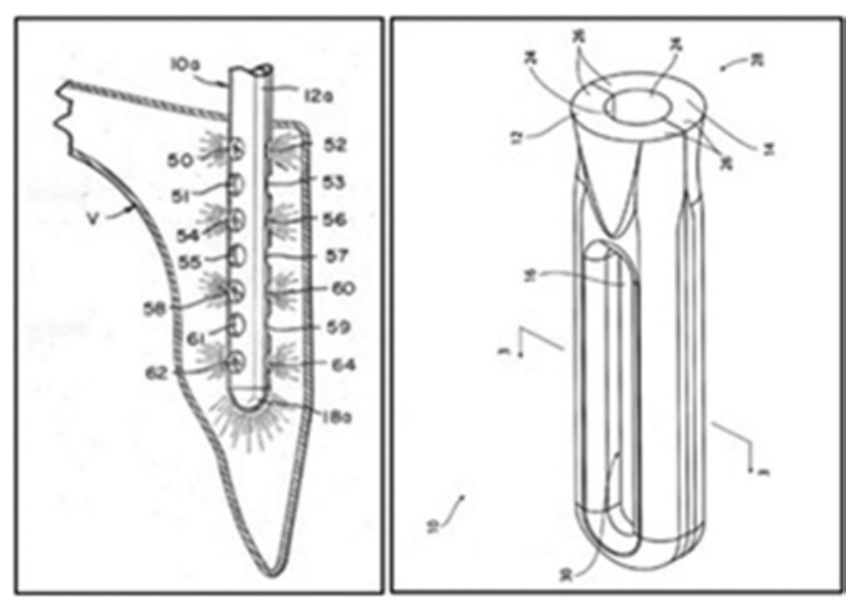

FIG. 7. Recently patented VC designs. Left: A catheter featuring a rounded transparent tip for use with an endoscope. From Dextradeur AJ, McCusker D, inventors: Fluid management catheter and methods of using same. US patent 20130253266 A1. September 26, 2013. Right: An occlusion-resistant catheter tip housing. From Mohan AA, Mohan $\mathrm{AL}$, Bernhard MJ, inventors: Occlusion resistant catheter and method of use. US patent US20140288479 A1. September 25, 2014. 
ability of implanted CSF shunts to allow many patients to lead relatively normal lives. Unfortunately, VC development has been disappointingly slow, and this component remains plagued by both mechanical and bio-adaptability issues. Additionally, the environment into which VCs are implanted is unique and complex, making it difficult to attain a comprehensive understanding of their in vivo functionality. Detailed imaging of operational VCs in action is not available, and in vitro experiments cannot accurately mimic what a VC would encounter over the course of its implanted lifetime. The solution to catheter obstruction continues to elude engineers and neurosurgeons alike, due to the many variables that influence obstruction rates. These include location of the catheter tip, varying CSF composition and flow characteristics among patients, and differences in catheter geometry among the many competing commercial designs available today. ${ }^{31}$ By gaining an improved understanding of each of these mechanisms and their interactive effects, the scientific community can optimize VC design to resist or prevent obstructions, thereby reducing emergency interventions, revision surgeries, and their associated risks to the patient.

\section{Acknowledgments}

We would like to thank undergraduate researcher Madeline J. Hayes for her editorial contributions. This research was supported by the Science Alliance at the University of Tennessee, Knoxville, through the Joint Directed Research and Development Collaborative Cohort Program Fellowship.

\section{References}

1. Ames RH: Ventriculo-peritoneal shunts in the management of hydrocephalus. J Neurosurg 27:525-529, 1967

2. Andrews EW: An improved technique in brain surgery. Glass tubes versus gold or platinum for subdural drainage of the lateral ventricles in internal hydrocephalus. Q Bull Northwest Univ Med Sch 12:171-179, 1911

3. Aschoff A, Kremer P, Hashemi B, Kunze S: The scientific history of hydrocephalus and its treatment. Neurosurg Rev 22:67-95, 1999

4. Banks BA, inventor: Ion beam sputter-etched ventricular catheter for hydrocephalus shunt. European patent EP0066685 A1. December 15, 1982

5. Bayston R, Milner RD: Antimicrobial activity of silicone rubber used in hydrocephalus shunts, after impregnation with antimicrobial substances. J Clin Pathol 34:1057-1062, 1981

6. Boergesen SE, inventor: Shunt system with coating and flow restricting component exerting a passive and essentially constant resistance to outflow. Worldwide patent WO2005051473 A2. June 9, 2005

7. Borgbjerg BM, Gjerris F, Albeck MJ, Hauerberg J, Børgesen SE: Frequency and causes of shunt revisions in different cerebrospinal fluid shunt types. Acta Neurochir (Wien) 136:189-194, 1995

8. Brydon HL, Bayston R, Hayward R, Harkness W: Reduced bacterial adhesion to hydrocephalus shunt catheters mediated by cerebrospinal fluid proteins. J Neurol Neurosurg Psychiatry 60:671-675, 1996

9. Brydon HL, Keir G, Thompson EJ, Bayston R, Hayward R, Harkness W: Protein adsorption to hydrocephalus shunt catheters: CSF protein adsorption. J Neurol Neurosurg Psychiatry 64:643-647, 1998

10. Cağavi F, Akalan N, Celik H, Gür D, Güçiz B: Effect of hydrophilic coating on microorganism colonization in silicone tubing. Acta Neurochir (Wien) 146:603-610, 2004
11. Chen HH, Riva-Cambrin J, Brockmeyer DL, Walker ML, Kestle JR: Shunt failure due to intracranial migration of BioGlide ventricular catheters. J Neurosurg Pediatr 7:408-412, 2011

12. Christens-Barry WA, Guarnieri M, Carson BS Sr: Fiberoptic delivery of laser energy to remove occlusions from ventricular shunts: technical report. Neurosurgery 44:345350, 1999

13. Colas A, Curtis J: Silicone biomaterials: history and chemistry, in Ratner BD, Hoffman AS, Schoen FJ, et al (eds): Biomaterials Science: An Introduction to Materials in Medicine, ed 2. Philadelphia: Elsevier, 2004, pp 80-85

14. Corbett JE, inventor: Ventricular catheter. US patent US4655745 A. April 7, 1987

15. Davidoff LM: Treatment of hydrocephalus: Historical review and description of a new method. JAMA Surg 18:1737-1762, 1929

16. De Nicola RR: Permanent artificial, silicone, urethra. J Urol 63:168-172, 1950

17. Demerdash A, Singh R, Loukas M, Tubbs RS: A historical glimpse into treating childhood hydrocephalus. Childs Nerv Syst [epub ahead of print], 2015

18. Dextradeur AJ, McCusker D, inventors: Fluid management catheter and methods of using same. US patent US20130253266 A1. September 26, 2013

19. Drake JM, Rose CS: The Shunt Book. New York: Wiley, 1995

20. Ellis MJ, Kazina CJ, Del Bigio MR, McDonald PJ: Treatment of recurrent ventriculoperitoneal shunt failure associated with persistent cerebrospinal fluid eosinophilia and latex allergy by use of an "extracted" shunt. J Neurosurg Pediatr 1:237-239, 2008

21. Fox R, Norton J: A novel device for the clearance and prevention of blockages within biomedical catheters. Med Eng Phys 36:1526-1529, 2014

22. Galarza M, Giménez Á, Pellicer O, Valero J, Amigó JM: New designs of ventricular catheters for hydrocephalus by 3-D computational fluid dynamics. Childs Nerv Syst 31:3748, 2015

23. Galarza M, Giménez Á, Valero J, Pellicer OP, Amigó JM: Computational fluid dynamics of ventricular catheters used for the treatment of hydrocephalus: a 3D analysis. Childs Nerv Syst 30:105-116, 2014

24. Ginsberg HJ, Drake JM, Peterson TM, Cobbold RS: Recanalization of obstructed cerebrospinal fluid ventricular catheters using ultrasonic cavitation. Neurosurgery 59 (4 Suppl 2):ONS403-ONS412, 2006

24. Ginsberg HJ, Sum A, Drake JM, Cobbold RS: Ventriculoperitoneal shunt flow dependency on the number of patent holes in a ventricular catheter. Pediatr Neurosurg 33:7-11, 2000

26. Go KG, Ebels EJ, van Woerden H: Experiences with recurring ventricular catheter obstructions. Clin Neurol Neurosurg 83:47-56, 1981

27. Gower DJ, Watson D, Harper D: e-PTFE ventricular shunt catheters. Neurosurgery 31:1132-1135, 1992

28. Haase J, Weeth R: Multiflanged ventricular Portnoy catheter for hydrocephalus shunts. Acta Neurochir (Wien) 33:213218, 1976

29. Hakim S: Observations on the physiopathology of the CSF pulse and prevention of ventricular catheter obstruction in valve shunts. Dev Med Child Neurol Suppl 20:42-48, 1969

30. Harris CA, McAllister JP II: Does drainage hole size influence adhesion on ventricular catheters? Childs Nerv Syst 27:1221-1232, 2011

31. Harris CA, McAllister JP II: What we should know about the cellular and tissue response causing catheter obstruction in the treatment of hydrocephalus. Neurosurgery 70:15891602,2012 
32. Harris CA, Resau JH, Hudson EA, West RA, Moon C, Black $\mathrm{AD}$, et al: Reduction of protein adsorption and macrophage and astrocyte adhesion on ventricular catheters by polyethylene glycol and N-acetyl-L-cysteine. J Biomed Mater Res A 98:425-433, 2011

33. Harris CA, Resau JH, Hudson EA, West RA, Moon C, McAllister JP II: Mechanical contributions to astrocyte adhesion using a novel in vitro model of catheter obstruction. Exp Neurol 222:204-210, 2010

34. Hazer DB, Mut M, Dinçer N, Saribas Z, Hazer B, Ozgen T: The efficacy of silver-embedded polypropylene-grafted polyethylene glycol-coated ventricular catheters on prevention of shunt catheter infection in rats. Childs Nerv Syst 28:839846,2012

35. Henle A: Beitrag zur pathologie und therapie des hydrocephalus. Mitt ad Grenzgeb Med Chir 1:264, 1896

36. Hermann EJ, Capelle HH, Tschan CA, Krauss JK: Electromagnetic-guided neuronavigation for safe placement of intraventricular catheters in pediatric neurosurgery. J Neurosurg Pediatr 10:327-333, 2012

37. Hyowon L, Kolahi K, Bergsneider M, Judy JW: Mechanical evaluation of unobstructing magnetic microactuators for implantable ventricular catheters. J Microelectromech Syst 23:795-802, 2014

38. Ingraham FD, Alexander E Jr, Matson DD: Polyethylene, a new synthetic plastic for use in surgery; experimental applications in neurosurgery. J Am Med Assoc 135:82-87, 1947

39. Janson CG, Romanova LG, Rudser KD, Haines SJ: Improvement in clinical outcomes following optimal targeting of brain ventricular catheters with intraoperative imaging. J Neurosurg 120:684-696, 2014

40. Keen WW: Surgery of the lateral ventricles of the brain. Lancet 136:553-555, 1890

41. Kehler U, Langer N, Gliemroth J, Meier U, Lemcke J, Sprung $\mathrm{C}$, et al: Reduction of shunt obstructions by using a peel-away sheath technique? A multicenter prospective randomized trial. Clin Neurol Neurosurg 114:381-384, 2012

42. Kestle J, Drake J, Milner R, Sainte-Rose C, Cinalli G, Boop F, et al: Long-term follow-up data from the Shunt Design Trial. Pediatr Neurosurg 33:230-236, 2000

43. Kosyrew A: Drainage der Hirnventrikel durch Netzstreifen. Langenbecks Arch Klin Chir Ver Dtsch Z Chir 141:691701, 1926

44. Krause F: Subcutane Dauerdrainage der Hirnventrikel beim Hydrocephalus. Verh Berl Med Ges 39:213-215, 1908

45. Lee CK, Tay LL, Ng WH, Ng I, Ang BT: Optimization of ventricular catheter placement via posterior approaches: a virtual reality simulation study. Surg Neurol 70:274-278, 2008

46. Lifshutz JI, Johnson WD: History of hydrocephalus and its treatments. Neurosurg Focus 11(2):E1, 2001

47. Lin J, Morris M, Olivero W, Boop F, Sanford RA: Computational and experimental study of proximal flow in ventricular catheters. Technical note. J Neurosurg 99:426-431, 2003

48. Lister J: On the antiseptic principle in the practice of surgery. BMJ 2:246-248, 1867

49. Medow JE: The permeable proximal catheter project: a novel approach to preventing shunt obstruction. Presented at the American Association of Neurological Surgeons Annual Meeting, Pediatric Section, New Orleans, 2005. (Abstract) (http://www.aans.org/en/AANS\%20and\%20JNSPG\%20 Publications/Abstracts\%20AANS/2004/December/The\%20 Permeable\%20Proximal\%20Catheter\%20Project $\% 20$ -\%20A\%20Nove1\%20Approach\%20To\%20Preventing\%20 Shunt $\% 20$ Obstruction.aspx?sc_database=web) [Accessed January 8, 2016]

50. Miller SL, Pinchuk L, inventors: Porous ventricular catheter. US patent US4767400 A. August 30, 1988

51. Mohan AA, Mohan AL, Bernhard MJ, inventors: Oc- clusion resistant catheter and method of use. US patent US20140288479 A1. September 25, 2014

52. Morota N, Ihara S, Araki T: Torkildsen shunt: re-evaluation of the historical procedure. Childs Nerv Syst 26:1705-1710, 2010

53. Mortazavi MM, Adeeb N, Griessenauer CJ, Sheikh H, Shahidi S, Tubbs RI, et al: The ventricular system of the brain: a comprehensive review of its history, anatomy, histology, embryology, and surgical considerations. Childs Nerv Syst 30:19-35, 2014

54. Nakamura S, Moriyasu N: Floating ventricular catheter. A new shunting device. Monogr Neural Sci 8:191-194, 1982

55. Nulsen FE, Spitz EB: Treatment of hydrocephalus by direct shunt from ventricle to jugular vain. Surg Forum 1951:399_ 403, 1951

56. Pattisapu JV, Trumble ER, Taylor KR, Howard PD, Kovach TM: Percutaneous endoscopic recanalization of the catheter: a new technique of proximal shunt revision. Neurosurgery 45:1361-1367, 1999

57. Piatt JH Jr, Cosgriff M: Monte Carlo simulation of cerebrospinal fluid shunt failure and definition of instability among shunt-treated patients with hydrocephalus. J Neurosurg 107 (6 Suppl):474-478, 2007

58. Portnoy HD: New ventricular catheter for hydrocephalic shunts. Technical note. J Neurosurg 34:702-703, 1971

59. Pudenz RH, Russell FE, Hurd AH, Shelden CH: Ventriculoauriculostomy; a technique for shunting cerebrospinal fluid into the right auricle; preliminary report. J Neurosurg 14:171-179, 1957

60. Rustamzadeh E, Lam CH: Cerebrospinal fluid shunts, in Johnson FE, Virgo K: The Bionic Human: Health Promotion for People With Implanted Prosthetic Devices. Totowa, NJ: Humana Press, 2006, pp 333-358

61. Ruzicka P, Ruzicka M, inventors: Cerebrospinal fluid shunt system. US patent US4950232 A. August 21, 1990

62. Sainte-Rose C, Piatt JH, Renier D, Pierre-Kahn A, Hirsch JF, Hoffman HJ, et al: Mechanical complications in shunts. Pediatr Neurosurg 17:2-9, 1991-1992

63. Schley D, Billingham J, Marchbanks RJ: A model of in-vivo hydrocephalus shunt dynamics for blockage and performance diagnostics. Math Med Biol 21:347-368, 2004

64. Sekhar LN, Moossy J, Guthkelch AN: Malfunctioning ventriculoperitoneal shunts. Clinical and pathological features. J Neurosurg 56:411-416, 1982

65. Senn N: Subcutaneous drainage in the surgical treatment of hydrocephalus internus. Alienist Neurol 24:316-324, 1903

66. Sharpe W: The operative treatment of hydrocephalus: A preliminary report of forty-one patients. Am J Med Sci 153:563-571, 1917

67. Sood S, Kim S, Ham SD, Canady AI, Greninger N: Useful components of the shunt tap test for evaluation of shunt malfunction. Childs Nerv Syst 9:157-162, 1993

68. Srinivasan VM, O'Neill BR, Jho D, Whiting DM, Oh MY: The history of external ventricular drainage. J Neurosurg 120:228-236, 2014

69. Stone JJ, Walker CT, Jacobson M, Phillips V, Silberstein HJ: Revision rate of pediatric ventriculoperitoneal shunts after 15 years. J Neurosurg Pediatr 11:15-19, 2013

70. Suresh S, Black RA: Electrospun polyurethane as an alternative ventricular catheter and in vitro model of shunt obstruction. J Biomater Appl 29:1028-1038, 2015

71. Sutherland G, Cheyne WW: The treatment of hydrocephalus by intracranial drainage. BMJ 1972:1155-1157, 1898

72. Sylvia K: AdvaMed Combination Products Workshop Case Study-Antibacterial Orthopedic and Neurological Devices. (http://www.fda.gov.tw/upload/189/ Content/2013011112025251410.pdf) [Accessed January 8, 2016]

73. Tavakoli B, Guo XY, Taylor RH, Kang JU, Boctor EM: Detecting occlusion inside a ventricular catheter using photo- 
acoustic imaging through skull. Proc SPIE Int Soc Opt Eng 8943:89434O, 2014

74. Thomale UW, Hosch H, Koch A, Schulz M, Stoltenburg G, Haberl EJ, et al: Perforation holes in ventricular catheters-is less more? Childs Nerv Syst 26:781-789, 2010

75. Thomale UW, Knitter T, Schaumann A, Ahmadi SA, Ziegler P, Schulz M, et al: Smartphone-assisted guide for the placement of ventricular catheters. Childs Nerv Syst 29:131-139, 2013

76. Torkildsen A: A follow-up study 14 to 20 years after ventriculocisternostomy. Acta Psychiatr Scand 35:113-121, 1960

77. Torkildsen A: A new palliative operation in cases of inoperable occlusion of the Sylvian aqueduct. Acta Psychiatr Scand 14:221-221, 1939

78. Tuli S, O’Hayon B, Drake J, Clarke M, Kestle J: Change in ventricular size and effect of ventricular catheter placement in pediatric patients with shunted hydrocephalus. Neurosurgery 45:1329-1335, 1999

79. Wan KR, Toy JA, Wolfe R, Danks A: Factors affecting the accuracy of ventricular catheter placement. J Clin Neurosci 18:485-488, 2011

80. Wichterle O, Lim D: Hydrophilic gels for biological use. Nature 185:117-118, 1960

81. Williams MA, McAllister JP, Walker ML, Kranz DA, Bergsneider M, Del Bigio MR, et al: Priorities for hydrocephalus research: report from a National Institutes of Health-sponsored workshop. J Neurosurg 107 (5 Suppl):345-357, 2007

82. Wong TT, Lee LS, Liu RS, Yeh SH, Chang T, Ho D, et al: Hydrogel ventriculo-subdural shunt for the treatment of hydrocephalus in children, in Matsumoto S, Tamaki N (eds): Hydrocephalus: Pathogenesis and Treatment. Tokyo: Springer, 1991, pp 438-449
83. Yamada SM, Kitagawa R, Teramoto A: Relationship of the location of the ventricular catheter tip and function of the ventriculoperitoneal shunt. J Clin Neurosci 20:99-101, 2013

84. Zemack G, Romner B: Seven years of clinical experience with the programmable Codman Hakim valve: a retrospective study of 583 patients. J Neurosurg 92:941-948, 2000

\section{Disclosures}

The authors report no conflict of interest concerning the materials or methods used in this study or the findings specified in this paper.

\section{Author Contributions}

Conception and design: Weisenberg, Killeffer. Acquisition of data: Weisenberg, TerMaath. Analysis and interpretation of data: TerMaath, Killeffer. Drafting the article: Weisenberg, Seaver. Critically revising the article: Weisenberg, TerMaath, Killeffer. Reviewed submitted version of manuscript: all authors. Approved the final version of the manuscript on behalf of all authors: Weisenberg. Administrative/technical/material support: TerMaath, Seaver, Killeffer.

\section{Correspondence}

Sofy H. Weisenberg, Institute of Biomedical Engineering, University of Tennessee, Knoxville, Dougherty Engineering Bldg., Knoxville, TN 37996-2210. email: sweisenb@vols.utk.edu. 